\title{
Furnace heat prediction and control model and its application to large blast furnace
}

https://doi.org/10.1515/htmp-2019-0049

Received Jul 31, 2018; accepted Aug 06, 2019

\begin{abstract}
Blast furnace heat is the key to the blast furnace's high efficiency and stable operation, and it is difficult to maintain a suitable temperature for large blast furnace operations. When designing the furnace heat prediction and control model, parameters with good reliability and measurability should be chosen to avoid using less accurate parameters and to ensure the accuracy and practicability of the model. This paper presents an effective model for large blast furnace temperature prediction and control. Using thermal equilibrium and the carbon-oxygen balance of the blast furnace's high-temperature zone, the slag-iron heat index was calculated. Using the relation between the molten iron temperature and slag-iron heat index, the furnace heat parameter can be calculated while production conditions are changed, which can guide furnace heat control.
\end{abstract}

Keywords: Furnace heat; Large blast furnace; Prediction and control; Thermal equilibrium; Carbon-oxygen balance

\section{Introduction}

Maintaining reasonable heat is the key to the blast furnace's high efficiency and stable operation. It is difficult to maintain suitable temperature for a large blast furnace, and temperatures that are too high or too low will not only cause blast furnace condition fluctuation, but also the production and technical indicators of the blast furnace and molten iron quality will be adversely affected. Because to the blast furnace production process is a complex reaction process involving high temperatures, external the factors

\footnotetext{
${ }^{\star}$ Corresponding Author: Man-sheng Chu: School of Metallurgy, Northeastern University, Shenyang 110819, China; Email: chums@smm.neu.edu.cn

Zhuang-nian Li, Zheng-gen Liu: School of Metallurgy, Northeastern University, Shenyang 110819, China

Gen-ji Ruan, Bao-feng Li: Ironmaking Plant, Shanxi Taigang Stainless Iron Shares Co., Ltd, Taiyuan 030003, China
}

that influence furnace temperature, and long time lag for large blast furnace heat change, furnace temperature control is difficult [1-4].

With the improvement in equipment and technology in the large blast furnace, the accuracy of certain blast furnace process parameters has clearly improved. For example, the air leaking rate of most small blast furnaces before was more than $8 \%$, but in the modern large blast furnace, it is usually less than $2 \%$. Meanwhile, the required accuracy for furnace temperature control is also improved. When designing the furnace heat prediction and control model, good parameters should be chosen for reliability and to avoid using less accurate parameters to ensure the accuracy and practicality of the model. In order to satisfy the temperature requirements, the operators of blast furnaces should predict the furnace temperature correctly according to the operation parameters and accurate adjustment measures. This paper presents an effective method for large blast furnace temperature prediction and control, which can guide furnace heat adjustment.

There are many factors that influence blast furnace heat. The main factors are blast parameters (including blast volume, rich oxygen flow, PCI rate, blast humidity, and blast temperature), coke load, gas utilization, operation yield, quality of raw materials and fuel (including: coke, coal, sintering, and pellet), heat load, and furnace dust. The furnace heat parameters should be calculated when the above mentioned conditions are changed.

The calculation model presented in this paper are as follows. Firstly, recent data on blast furnace operation were collected, as the benchmark data for blast furnace operation. Secondly, the blast furnace benchmark data were used in the blast furnace high temperature thermal equilibrium and carbon-oxygen balance equations, the theoretical PCI rate was calculated, the theoretical direct reduction of carbon consumption under the benchmark conditions and slag-iron heat index was calculated. Thirdly, the blast furnace target parameters was used in the thermal equilibrium and carbon-oxygen balance equations for the blast furnace high-temperature zone, target slag-iron heat index was calculated, the relation between the temperature and slag-iron heat index was established, and the

OOpen Access. (C) 2019 Zhuang-nian Li et al., published by De Gruyter. (cc) BY 4.0 License 
molten iron temperature and [Si] were calculated; Finally, corresponding to the target molten iron temperature, the slag-iron heat index was used in the blast furnace high temperature thermal equilibrium and carbon-oxygen balance equations, and the PCI rate and the quantity of coal needed were calculated, such that heat control could be achieved.

\section{Calculation of the theoretical PCI rate}

First, the benchmark parameters should be statistics that can represent the recent operating status of the blast furnace (the " 0 " on the right is marked as the benchmark parameter), and the statistical parameters are shown in Table 1.

Atmospheric humidity (\%):

$$
f^{0}=\frac{22.4 \times \mathrm{H}_{\mathrm{ATS}}^{0}}{1000 \times 18}
$$

Amount of $\mathrm{O}_{2}$ per minute $(\mathrm{Nm} 3 / \mathrm{min})$ :

$$
\begin{aligned}
O_{2 \_}^{0} \mathrm{~b} & =\left[0.21 \times\left(1-f^{0}\right)+0.5 \times f^{0}\right] \times V_{\mathrm{b}}^{0}+\frac{\mathrm{V}_{\text {coal }}^{0}}{60} \\
& +\frac{\lambda_{o 2} \times \mathrm{V}_{02}^{0}}{60}+\frac{1000 \times 22.4 \times \mathrm{H}_{A D D}^{0}}{2 \times 18 \times 60}
\end{aligned}
$$

where, $\lambda_{O 2}$ is the quality percentage of $\mathrm{O}_{2}$ in rich oxygen, which is $99.7 \%$.

Oxygen consumption in combustion per ton iron $(\mathrm{Nm} 3 / \mathrm{tFe})$ :

$$
O_{\text {CBT }}^{0}=\frac{1440 \times O_{2 \_b}^{0}}{P^{0}}
$$

Carbon consumption in combustion per ton iron $(\mathrm{kg} / \mathrm{tFe})$ :

$$
C_{\mathrm{CBT}}^{0}=O_{\mathrm{CBT}}^{0} \times \frac{24}{22.4}
$$

Under normal circumstances, the ratio of unburned coal powder to furnace dust is lower, and the influence on calculation of the thermal equilibrium and carbon-oxygen balance is not larger, but as the PCI rate increases, unburned coal powder into the furnace dust markedly increases, MO should be the quantity of coal that actually reacts in the furnace, which is the total quantity of coal minus the quantity of coal increased in the furnace dust. Assuming that the coal is burned completely in the tuyere zone, then carbon consumption of coke in combustion per ton iron $(\mathrm{kg} / \mathrm{tFe})$

$$
C_{C B T_{-} \text {coke }}^{0}=C_{C B T}^{0}-\mathrm{M}^{0} \times \omega^{0} \mathrm{C}_{\text {coal }} / 100
$$

Amount of coke gasification per ton iron $(\mathrm{kg} / \mathrm{tFe})$ :

$$
C_{\text {GAS_coke }}^{0}=K^{0} \times \omega^{0}\left(C_{\text {coke }}\right) / 100-C_{C B R}^{0}-C_{\text {dust }}^{0}
$$

Carbon consumption by direct reduction per ton iron $(\mathrm{kg} / \mathrm{tFe})$ :

$$
C_{\mathrm{dFe}}^{0}=C_{G A S_{-} \text {coke }}^{0}-C_{C B T_{-} \text {coke }}^{0}-C_{\mathrm{da}}^{0}
$$

where $C_{d a}^{0}$ represents carbon consumption of elements reduced other than iron $(\mathrm{kg} / \mathrm{tFe})$ and $C_{C B R}^{0}$ is the amount of carburizing in pig iron $(\mathrm{kg} / \mathrm{tFe}) . C_{\text {dust }}^{0}$ is the carbon content in dust per ton iron $(\mathrm{kg} / \mathrm{tFe})$.

The amount of oxygen entering into the blast furnace gas from raw materials and fuel $(\mathrm{kg} / \mathrm{tFe})$ is

$$
\begin{aligned}
\mathrm{O}_{M}^{0} & =\mathrm{m}_{\text {sint }}^{0} \times\left[\omega^{0}\left(\mathrm{Fe}_{2} \mathrm{O}_{3 \text { sint }}\right) / 100 \times 48 / 160\right. \\
& +\omega^{0}\left(\mathrm{FeO}_{\text {sint }} / 100 \times 16 / 72\right]+\mathrm{m}_{\text {pel1 }}^{0} \\
& \times\left[\omega^{0}\left(\mathrm{Fe}_{2} \mathrm{O}_{3 \text { pel1 }}\right) / 100 \times 48 / 160+\omega^{0}\left(\mathrm{FeO}_{\text {pel } 1}\right) / 100\right. \\
& \times 16 / 72]-\mathrm{m}_{\text {dust }}^{0} \times\left[\omega^{0}\left(\mathrm{Fe}_{2} \mathrm{O}_{3 \text { dust }}\right) / 100 \times 48 / 160\right. \\
& \left.+\omega^{0}\left(\mathrm{FeO}_{\text {dust }}\right) / 100 \times 16 / 72\right]-\mathrm{m}_{\text {slag }}^{0} \times \omega^{0}(\mathrm{FeO}) / 100 \\
& \times 16 / 72+\mathrm{M}^{0} \times\left[\omega^{0}\left(\mathrm{H}_{2} \mathrm{O}_{\text {coal }}\right) / 100 /(1\right. \\
& \left.\left.-\omega^{0}\left(\mathrm{H}_{2} \mathrm{O}_{\text {coal }}\right) / 100\right) / 18 \times 16+\omega^{0}\left(\mathrm{O}_{\text {coal }}\right) / 100\right]+\mathrm{K}^{0} \\
& \times \omega^{0}\left(\mathrm{O}_{\text {coke }} / 100+10 \times\left([\mathrm{Si}]^{0} \times 32 / 28+[\mathrm{Mn}]^{0} \times 16 / 55\right.\right. \\
& \left.+[\mathrm{P}]^{0} \times 80 / 62\right)+\mathrm{m}_{\text {slag }}^{0} \times(\mathrm{S})^{0} / 100 \times 16 / 32
\end{aligned}
$$

Amount of moles $\mathrm{H}$ containing in per $\mathrm{kg}$ coal $(\mathrm{kmol} / \mathrm{kg})$ :

$$
\begin{aligned}
\mathrm{n}^{0}\left(\mathrm{H}_{\text {coal }}\right) & =\left[\omega^{0}\left(\mathrm{H}_{\text {coal }}\right) / 100 / 2\right. \\
& \left.+\omega^{0}\left(H_{2} O_{\text {coal }}\right) / 100 /\left(1-\omega^{0}\left(H_{2} O_{\text {coal }}\right) / 100\right) / 18\right]
\end{aligned}
$$

Use the above calculation results in the carbon-oxygen balance equation [5]:

$$
\begin{aligned}
\eta_{C O}^{0} & =\frac{O_{M}^{0} / 16-C_{d F e}^{0} / 12}{M^{0} \times \omega^{0}\left(C_{\text {coal }}\right) / 100+C_{G A S_{-} \text {coke }}^{0} / 12} \\
- & \frac{\eta_{H_{2}} \times v_{H_{2} O \_b}^{0} \times C_{C B T}^{0} / 22.4+M^{0} \times \mathrm{n}^{0}\left(\mathrm{H}_{\text {coal }}\right)}{M^{0} \times \omega^{0}\left(C_{\text {coal }}\right) / 100+C_{G A S_{-} \text {coke }}^{0} / 12}
\end{aligned}
$$

The denominator is the total volume of carbon gas in moles, the numerator is the total volume of $\mathrm{CO}_{2}$ gas in moles, and the amount is equal to the total amount of $\mathrm{CO}_{2}$ generated from reaction of $\mathrm{CO}$ and $\mathrm{O}$. $\mathrm{CO}$ comes from the tuyere combustion and $\mathrm{O}$ from raw materials and fuel, minus the mole amount of $\mathrm{CO}$ that derived from the direct reduction process of $\mathrm{C}$ and $\mathrm{FeO}$, and minus the molar volume of $\mathrm{H}_{2} \mathrm{O}$ that is derived from the direct reduction of $\mathrm{H}$ and $\mathrm{O}$. $\eta_{H_{2}}$ indicates the utilization ratio of hydrogen in the high temperature zone, which is generally $30 \%-50 \%$. 
Table 1: Benchmark parameters of blast furnace.

\begin{tabular}{|c|c|c|c|}
\hline Item & Symbol & Units & Benchmark parameter \\
\hline Blast volume & $\mathrm{V}_{b}$ & $\mathrm{Nm}^{3} / \mathrm{min}$ & 6096.00 \\
\hline Rich oxygen flow & $\mathrm{V}_{o 2}$ & $\mathrm{Nm}^{3} / \mathrm{h}$ & 15929.00 \\
\hline Atmospheric humidity & $\mathrm{H}_{A T S}$ & $\mathrm{~g} / \mathrm{m}^{3}$ & 3.00 \\
\hline Humidification quantity & $\mathrm{H}_{A D D}$ & $\mathrm{t} / \mathrm{h}$ & 0.10 \\
\hline Blast temperature & BT & ${ }^{\circ} \mathrm{C}$ & 1267.00 \\
\hline Gas utilization ratio & $\eta_{C O}$ & - & $49.51 \%$ \\
\hline Molten iron temperature & PT & ${ }^{\circ} \mathrm{C}$ & 1515.00 \\
\hline Coke rate & $\mathrm{K}$ & $\mathrm{kg} / \mathrm{tFe}$ & 326.56 \\
\hline $\mathrm{PCl}$ rate(dry) & M & $\mathrm{kg} / \mathrm{tFe}$ & 190.60 \\
\hline Yield of iron & $\mathrm{P}$ & $t / d$ & 9458.72 \\
\hline Heat load & $\mathrm{Q}_{\text {load }}$ & $10 \mathrm{MJ} / \mathrm{h}$ & 8453.00 \\
\hline Carbon in coke & $\omega\left(\mathrm{C}_{\text {coke }}\right)$ & $\%$ & 87.29 \\
\hline Ash in coke & $\omega\left(\mathrm{A}_{\text {coke }}\right)$ & $\%$ & 11.67 \\
\hline Carbon in coal & $\omega\left(\mathrm{C}_{\text {coal }}\right)$ & $\%$ & 69.97 \\
\hline Ash in coal & $\omega\left(\mathrm{A}_{\text {coal }}\right)$ & $\%$ & 10.86 \\
\hline Consumption of sintering per ton iron & $\mathrm{M}_{\text {sint }}$ & $\mathrm{kg} / \mathrm{tFe}$ & 1213.30 \\
\hline Consumption of pellets per ton iron & $\mathrm{M}_{\text {pell }}$ & $\mathrm{kg} / \mathrm{tFe}$ & 391.11 \\
\hline$[\mathrm{Si}]$ & {$[\mathrm{Si}]$} & $\%$ & 0.42 \\
\hline$[\mathrm{Fe}]$ & {$[\mathrm{Fe}]$} & $\%$ & 94.72 \\
\hline$[\mathrm{C}]$ & {$[\mathrm{C}]$} & $\%$ & 4.70 \\
\hline$[\mathrm{Mn}]$ & {$[\mathrm{Mn}]$} & $\%$ & 0.04 \\
\hline$[\mathrm{P}]$ & {$[\mathrm{P}]$} & $\%$ & 0.07 \\
\hline [Ti] & {$[\mathrm{Ti}]$} & $\%$ & 0.03 \\
\hline Slag rate & $\mathrm{M}_{\text {slag }}$ & $\mathrm{kg} / \mathrm{tFe}$ & 305.00 \\
\hline Moisture in coal & $\omega\left(\mathrm{H}_{2} \mathrm{O}_{\text {coal }}\right)$ & $\%$ & 1.32 \\
\hline 0 in coal & $\omega\left(\mathrm{O}_{\text {coal }}\right)$ & $\%$ & 8.21 \\
\hline $\mathrm{Fe}_{2} \mathrm{O}_{3}$ in Sintering & $\omega\left(\mathrm{Fe}_{2} \mathrm{O}_{3 \sin t}\right)$ & $\%$ & 72.44 \\
\hline FeO in Sintering & $\omega\left(\mathrm{FeO}_{\text {sint }}\right)$ & $\%$ & 9.59 \\
\hline $\mathrm{Fe}_{2} \mathrm{O}_{3}$ in pellets & $\omega\left(\mathrm{Fe}_{2} \mathrm{O}_{3 p e l l}\right)$ & $\%$ & 90.88 \\
\hline $\mathrm{FeO}$ in pellets & $\omega\left(\mathrm{FeO}_{\text {pell }}\right)$ & $\%$ & 0.66 \\
\hline FeO in Slag & $(\mathrm{FeO})$ & $\%$ & 0.04 \\
\hline S in Slag & $(\mathrm{S})$ & $\%$ & 1.02 \\
\hline Furnace dust production per ton iron & $\mathrm{M}_{\text {dust }}$ & $\mathrm{kg} / \mathrm{tFe}$ & 17.00 \\
\hline $\mathrm{Fe}_{2} \mathrm{O}_{3}$ in dust & $\omega\left(\mathrm{Fe}_{2} \mathrm{O}_{3 d u s t}\right)$ & $\%$ & 48.12 \\
\hline FeO in dust & $\omega\left(\mathrm{FeO}_{\text {dust }}\right)$ & $\%$ & 6.82 \\
\hline C in dust & $\omega\left(\mathrm{C}_{\text {dust }}\right)$ & $\%$ & 20.25 \\
\hline 0 in coke & $\omega\left(\mathrm{O}_{\text {coal }}\right)$ & $\%$ & 0.70 \\
\hline Blast volume by PC & $\mathrm{V}_{\text {coal }}$ & $\mathrm{Nm}^{3} / \min$ & 2873.00 \\
\hline Nitrogen volume by PC & $\mathrm{V}_{\text {Coal_N2 }}$ & $\mathrm{Nm}^{3} / \mathrm{h}$ & 4000.00 \\
\hline Hydrogen utilization & $\eta_{H 2}$ & - & $40.00 \%$ \\
\hline
\end{tabular}

Transform equation (9) to be

$$
\begin{aligned}
& M^{0}=\frac{12 \times O_{M}^{0} / 16+C_{C B T}^{0}+C_{d a}^{0}}{\left(\eta_{C O}^{0}+1\right) \times \omega^{0}\left(C_{\text {coal }}\right) / 100+12 \times n^{0}\left(H_{\text {coal }}\right)} \\
& -\frac{\left(\eta_{C O}^{0}+1\right) \times C_{G A S_{-} \text {coke }}^{0}-12 \times \eta_{H_{2}} \times v_{H_{2} O \_b}^{0} \times C_{C B T}^{0} / 22.4}{\left(\eta_{C O}^{0}+1\right) \times \omega^{0}\left(C_{\text {coal }}\right) / 100+12 \times n^{0}\left(H_{\text {coal }}\right)}
\end{aligned}
$$

Use $\mathrm{M}^{0}$ in equations (5) and (7), $C_{C B T \text { coke }}^{0}$ and $C_{\mathrm{dFe}}^{0}$ can be calculated.

Comparing the theoretical PCI rate calculated from the above equation with the actual coal, if the deviation is not large, it can be directly used in the next calculation. However, the calculated data need to be checked for mis- 
takes or parameter distortion. Based on this premise, the deviation between theoretical and actual quantity of coal needed (or PCI rate) is adjusted to ensure the accuracy of the calculated results.

\section{Calculation of slag-iron heat index [6-10]}

Total volume of hot air coming into the blast furnace per minute $\left(\mathrm{Nm}^{3} / \mathrm{min}\right)$ :

$$
\begin{aligned}
\mathrm{V}_{H A}^{0} & =\mathrm{V}_{\mathrm{b}}^{0}+\mathrm{V}_{o 2}^{0} / 60+\mathrm{V}_{\text {coal }}^{0} / 60+\mathrm{V}_{\text {coal_N } 2}^{0} / 60 \\
& +\mathrm{H}_{A D D}^{0} \times 1000 \times 22.4 / 18 / 60
\end{aligned}
$$

The ratio of $\mathrm{H}_{2} \mathrm{O}$ in hot air:

$$
\begin{aligned}
\varphi^{0}\left(\mathrm{H}_{2} \mathrm{O}\right) & =\left(\mathrm{H}_{A D D}^{0} \times 1000000 / 60\right. \\
& \left.+\left(\mathrm{V}_{\mathrm{b}}^{0}+\mathrm{V}_{\text {coal }}^{0} / 60\right) \times \mathrm{H}_{A T S}^{0}\right) \times 22.4 / 18 / 1000 / \mathrm{V}_{b}^{0}
\end{aligned}
$$

The ratio of $\mathrm{O}_{2}$ in hot air after the decomposition of $\mathrm{H}_{2} \mathrm{O}$ :

$$
\begin{aligned}
\varphi_{1}^{0}\left(\mathrm{O}_{2}\right) & =\left[\left(0.21+0.29 \times \mathrm{H}_{A T S}^{0} \times 22.4 / 18 / 1000\right)\right. \\
& \times\left(\mathrm{V}_{\mathrm{b}}^{0}+\mathrm{V}_{\text {coal }}^{0} / 60\right)+\mathrm{V}_{\mathrm{o} 2}^{0} / 60 \times \lambda_{\mathrm{o} 2}+\mathrm{H}_{A D D}^{0} \\
& \times 1000 \times 22.4 / 18 / 2 / 60] / \mathrm{V}_{b}^{0}
\end{aligned}
$$

The ratio of $\mathrm{O}_{2}$ in hot air before the decomposition of $\mathrm{H}_{2} \mathrm{O}$ :

$$
\varphi_{2}^{0}\left(\mathrm{O}_{2}\right)=\varphi_{1}^{0}\left(\mathrm{O}_{2}\right)-\varphi^{0}\left(\mathrm{H}_{2} \mathrm{O}\right) / 2
$$

The ratio of $\mathrm{N}_{2}$ in hot air:

$$
\varphi^{0}\left(\mathrm{~N}_{2}\right)=1-\varphi_{2}^{0}\left(\mathrm{O}_{2}\right)-\varphi^{0}\left(\mathrm{H}_{2} \mathrm{O}\right)
$$

The volume of hot air needed to burn per kilogram carbon $\left(\mathrm{Nm}^{3} / \mathrm{kg}\right)$ :

$$
v_{H A}^{0}=22.4 / 24 / \varphi_{1}^{0}\left(\mathrm{O}_{2}\right)
$$

The volume of $\mathrm{H}_{2} \mathrm{O}$ in hot air to burn per kilogram carbon $\left(\mathrm{Nm}^{3} / \mathrm{kg}\right)$ :

$$
v_{\mathrm{H}_{2} \mathrm{O}-\mathrm{HA}}^{0}=v_{\mathrm{HA}}^{0} \times \varphi^{0}\left(\mathrm{H}_{2} \mathrm{O}\right)
$$

The volume of $\mathrm{O}_{2}$ in hot air to burn per kilogram carbon $\left(\mathrm{Nm}^{3} / \mathrm{kg}\right)$ :

$$
v_{O_{2} \_H A}^{0}=v_{H A}^{0} \times \varphi_{2}^{0}\left(\mathrm{O}_{2}\right)
$$

The volume of $\mathrm{N}_{2}$ in hot air to burn per kilogram carbon $\left(\mathrm{Nm}^{3} / \mathrm{kg}\right)$ :

$$
v_{N_{2}-H A}^{0}=v_{H A}^{0} \times \varphi^{0}\left(\mathrm{~N}_{2}\right)
$$

The volume of $\mathrm{CO}$ generated by burning per kilogram carbon $\left(\mathrm{Nm}^{3} / \mathrm{kg}\right)$ :

$$
v_{C O \_G A S}^{0}=22.4 / 12
$$

The volume of $\mathrm{N}_{2}$ generated by burning per kilogram carbon $\left(\mathrm{Nm}^{3} / \mathrm{kg}\right)$ :

$$
v_{N_{2} G A S}^{0}=v_{N_{2 \_} H B}^{0}
$$

The volume of $\mathrm{H}_{2}$ generated by burning per kilogram carbon $\left(\mathrm{Nm}^{3} / \mathrm{kg}\right)$ :

$$
v_{H_{2} G A S}^{0}=22.4 / 24 / \phi_{1}^{0}\left(O_{2}\right) \times \phi^{0}\left(H_{2} O\right) \times\left(1-\eta_{H_{2}}\right)
$$

The volume of $\mathrm{H}_{2} \mathrm{O}$ generated by burning per kilogram carbon $\left(\mathrm{Nm}^{3} / \mathrm{kg}\right)$ :

$$
v_{\mathrm{H}_{2} \mathrm{O}_{-} \mathrm{GAS}}^{0}=22.4 / 24 / \phi_{1}^{0}\left(\mathrm{O}_{2}\right) \times \phi^{0}\left(\mathrm{H}_{2} \mathrm{O}\right) \times \eta_{\mathrm{H}_{2}}
$$

Thermal revenue by burning per kilogram carbon in high-temperature zone $(\mathrm{kJ} / \mathrm{kg}(\mathrm{C}))$ :

$$
\begin{aligned}
& q_{C_{-} C B T}^{0}=9800+\left(q_{C O \_H A}^{0} \times v_{C O \_H A}^{0}+q_{N_{2} O_{A}}^{0}\right. \\
& \left.\times v_{\mathrm{N}_{2} \mathrm{HA}}^{0}+q_{\mathrm{H}_{2} \mathrm{O}_{-} \mathrm{HA}}^{0} \times v_{\mathrm{H}_{2} \mathrm{O}_{-} \mathrm{HA}}^{0}\right)-10785 \times v_{\mathrm{H}_{2} \mathrm{O} \_\mathrm{HA}}^{0} \\
& -q_{H_{-} R D C} \times \eta_{H_{2}} \times v_{H_{2} O_{-} H B}^{0}-\left(q_{C O}^{0} G A S \times v_{C O}^{0} G A S\right. \\
& +q_{N_{2} G A S}^{0} \times v_{N_{2} G A S}^{0}+q_{H_{2} O_{-} G A S}^{0} \times v_{H_{2} O}^{0} O_{-} G A S \\
& \left.+q_{H_{2-} G A S}^{0} \times v_{H_{2-} G A S}^{0}\right)
\end{aligned}
$$

where, $q_{\mathrm{x} \_B}^{0}$ indicate the heat enthalpy of $\mathrm{x}$ gas at $\mathrm{s}$ specific under blast temperature, and $q_{\mathrm{x}_{-} G A S}^{0}$ represents the heat enthalpy of $\mathrm{x}$ gas at the limit temperature $\left(950^{\circ} \mathrm{C}\right)$. The heat enthalpy calculation uses the method mentioned in the literature [6]. $q_{H_{\_} R D C}$ is the thermal consumption of hydrogen reduced per kmol.

While burning coke, thermal revenue burning per kilogram carbon $(\mathrm{kJ} / \mathrm{kg}(\mathrm{C}))$ is

$$
\begin{aligned}
q_{C_{-} C B T_{-} \text {coke }}^{0} & =q_{C_{-} C B T}^{0}-\bar{C}_{\text {coke }} \times \frac{\omega^{0} A_{\text {coke }}}{\omega^{0} C_{\text {coke }}} \\
& \times\left(\mathrm{t}_{\text {slag }}-\mathrm{t}_{\text {lim it }}\right)
\end{aligned}
$$

While burning coal, thermal revenue burning per kilogram coal $(\mathrm{kJ} / \mathrm{kg}(\mathrm{C}))$ is

$$
\begin{aligned}
q_{\text {coal }}^{0} & =q_{C_{-} C B T}^{0} \times \omega^{0}\left(\mathrm{C}_{\text {coal }}\right) / 100-q_{H_{-} R D C} \\
& \times \eta_{H_{2}} \times \mathrm{n}^{0}\left(\mathrm{H}_{\text {coal }}\right)-\mathrm{q}_{D E C}
\end{aligned}
$$

Thermal consumption of carbon per kilogram directly reduced $(\mathrm{kJ} / \mathrm{kg}(\mathrm{C}))$ is

$$
q_{d F e}^{0}=q_{d F e_{-} R D C}^{0}+\bar{C}_{\text {coke }} \times \frac{\omega^{0} A_{\text {coke }}}{\omega^{0} C_{\text {coke }}} \times\left(\mathrm{t}_{\text {slag }}-\mathrm{t}_{\text {limit }}\right)
$$

Heat loss per ton iron $(\mathrm{kJ} / \mathrm{tFe})$ :

$$
Q_{\text {loss }}^{0}=\lambda_{\text {loss }} \times Q_{\text {load }} \times 10000 \times 24 / P^{0}
$$


Using the above calculation results in the thermal equilibrium and carbon-oxygen balance equations to calculate the blast furnace high-temperature zone, the target slag-iron heat index $(\mathrm{kJ} / \mathrm{tFe})$ is

$$
\begin{aligned}
Q_{\text {heat }}^{0} & =q_{C_{C} C B T}^{0} \times C_{C B T_{-} \text {coke }}^{0}+q_{\text {coal }}^{0} \times M^{0}-q_{d F e}^{0} \\
& \times C_{d F e}^{0}-Q_{\text {loss }}^{0}
\end{aligned}
$$

The slag-iron heat index indicates the heat of iron and slag per ton of iron, which represent the heat level of the blast furnace. The higher the slag-iron heat index is, the higher the furnace heat is.

\section{Furnace heat prediction and control}

Using the target parameters (or actual running parameters) in the thermal equilibrium and carbon-oxygen balance equations,

$$
\begin{aligned}
& \lambda_{\text {heat }} \times Q_{\text {heat }}^{0}=q_{C_{-} C B T} \times C_{C B T_{-} \text {coke }}+q_{\text {coal }} \times M \\
& -q_{d F e} \times C_{d F e}-Q_{\text {loss }} \\
& \eta_{C O}=\frac{O_{M} / 16-C_{d F e} / 12}{M \times \omega\left(C_{\text {coal }}\right) / 100+C_{G A S_{-} \text {coke }} / 12} \\
& -\frac{\eta_{\mathrm{H}_{2}} \times v_{\mathrm{H}_{2} \mathrm{O} \_\mathrm{b}} \times C_{C B T} / 22.4+M \times \mathrm{n}\left(\mathrm{H}_{\text {coal }}\right)}{M \times \omega\left(C_{\text {coal }}\right) / 100+C_{G A S_{-} \text {coke }} / 12}
\end{aligned}
$$

where,

$$
\begin{gathered}
C_{G A S_{-} \text {coke }}=K \times \omega\left(C_{\text {coke }}\right) / 100-C_{C B R}-C_{d u s t} \\
C_{C B T_{-} \text {coke }}=C_{G A S_{-} \text {coke }}-C_{\mathrm{dFe}}-C_{d a} \\
C_{C B T}=C_{C B T_{-} \text {coke }}+M \times \omega\left(\mathrm{C}_{\text {coal }}\right) / 100 \\
C_{C B T}=C_{G A S_{-} \text {coke }}-C_{\mathrm{dFe}}-C_{d a}+M \times \omega\left(C_{\text {coal }}\right) / 100
\end{gathered}
$$

The calculation method of $O_{M}, C_{d a}, C_{C B R}, C_{\text {dust }}$, $\mathrm{n}\left(\mathrm{H}_{\text {coal }}\right), q_{C_{-} C B T}, q_{\text {coal }}, q_{d F e}$ is the same as $O_{M}^{0}, C_{d a}^{0}, C_{C B R}^{0}$, $C_{\text {dust }}^{0}, \mathrm{n}^{0}\left(\mathrm{H}_{\text {coal }}\right), q_{C_{-} \text {CBT }}^{0}, q_{\text {coal }}^{0}, q_{d F e}^{0}$.

$Q_{\text {heat }}=\lambda_{\text {heat }} \times Q_{\text {heat }}^{0}, \lambda_{\text {heat }}$ is heat coefficient, and when $\lambda_{\text {heat }}=1$, furnace heat can be considered equivalent to the benchmark furnace heat.

The formula of molten iron temperature prediction:

$$
\mathrm{T}_{\text {iron }}=\left[1+\alpha \times \lambda_{\text {heat }}-1\right] \times T_{\text {iron }}^{0}
$$

where, $\alpha$ is the correlation coefficient between molten iron temperature and slag-iron heat index.
Using the above calculation results in equations (31) and (32), only $\mathrm{M}$ and $\mathrm{C}_{d F e}$ are the two unknowns in the equation [5].

$$
\begin{aligned}
& q_{\text {coal }} \times M+\left(q_{d F e}-q_{C_{-} C B T}\right) \times C_{d F e}=\lambda_{\text {heat }} \times Q_{\text {heat }}^{0} \\
& -q_{C_{-} C B T} \times\left(C_{G A S_{C} \text { coke }}-C_{\text {da }}\right)+Q_{\text {loss }}
\end{aligned}
$$

$\left[\frac{\eta_{\mathrm{CO}} \times \omega\left(C_{\text {coal }}\right) / 100}{12}+\eta_{H_{2}}\right.$

$$
\begin{aligned}
& \left.\times\left(\frac{v_{H_{2} O} \mathrm{HB}_{B} \times \omega\left(C_{\text {coal }}\right) / 100}{22.4}+\mathrm{n}\left(H_{\text {coal }}\right)\right)\right] \times M \\
& +\left(\frac{1}{12}+\frac{\eta_{H_{2}} \times v_{H_{2} O} \mathrm{O}_{B}}{22.4}\right) \times C_{\mathrm{dFe}}=\frac{O_{M}}{16} \\
& -\frac{\eta_{H_{2}} \times v_{H_{2} O \_H B} \times\left(C_{G A S \_c o k e}-C_{\mathrm{da}}\right)}{22.4}-\frac{\eta_{C O} \times C_{G A S \_c o k e}}{12}
\end{aligned}
$$

$\mathrm{M}$ and $\mathrm{C}_{d F e}$ can be obtained from equations (38) and (39), and the result can be use in equations (34) and (35) to calculate $\mathrm{C}_{C B T_{-} \text {coke }}$ and $\mathrm{C}_{C B T}$.

The estimated daily output of molten iron $(\mathrm{t} / \mathrm{d})$ :

$$
P=\frac{1440 \times O_{2 \_H B}}{C_{C B T} \times 22.4 / 24}
$$

The quantity of coal needed $(\mathrm{t} / \mathrm{h})$ :

$$
\begin{aligned}
\mathrm{m}_{\text {coal }} & =P \times\left[M+\left(M^{\mathrm{a}}-M^{0}\right)\right] / 1 \\
& -\omega\left(H_{2} O_{\text {coal }}\right) / 100 / 1000 / 24
\end{aligned}
$$

\section{Application of blast furnace heat control}

Using the benchmark parameters of Table 1 in the above calculation equation, the calculation results are shown in Table 2.

According to the calculations in the above section, while the operation parameters of the blast furnace are changed to maintain constant furnace heat, the quantity of the coal needed or other control parameters can be calculated.

In actual production, to stabilize the furnace conditions and heat, the operating parameters are often kept constant, but $\eta_{c o}$ changes frequently. Through the above section, the estimated fuel rate and quantity of coal needed can be calculated for different $\eta_{C O}$, and the calculation results as shown in Figure 1.

When the heat of blast furnace needs to be adjusted, assuming that only the quantity of coal is adjusted, other operating parameters remain the same, and at the same 
Table 2: Heat calculation results of blast furnace.

\begin{tabular}{|c|c|c|c|}
\hline Item & Symbol & Units & Results \\
\hline Atmospheric humidity & $f$ & - & $0.37 \%$ \\
\hline Ratio of $\mathrm{O}_{2}$ in hot air & $\mathrm{O}_{2} \mathrm{HB}_{\mathrm{B}}$ & $\mathrm{Nm}^{3} / \mathrm{min}$ & 1562.59 \\
\hline Oxygen consumption in combustion per ton iron & $\mathrm{O}_{C B T}$ & $\mathrm{Nm}^{3} / \mathrm{tFe}$ & 237.89 \\
\hline Carbon consumption in combustion per ton iron & $\mathrm{C}_{C B T}$ & $\mathrm{~kg} / \mathrm{tFe}$ & 254.88 \\
\hline Amount of coke gasification per ton iron & $\mathrm{C}_{\text {GAS_coke }}$ & $\mathrm{kg} / \mathrm{tFe}$ & 234.60 \\
\hline $\begin{array}{l}\text { Amount of oxygen entering blast furnace gas } \\
\text { from raw materials and fuel }\end{array}$ & $\mathrm{O}_{M}$ & $\mathrm{~kg} / \mathrm{tFe}$ & 421.52 \\
\hline Amount of moles $\mathrm{H}$ in per kilogram coal & $\mathrm{N}\left(\mathrm{H}_{\text {coal }}\right)$ & $\mathrm{kmol} / \mathrm{kg}$ & 0.018 \\
\hline $\mathrm{PCl}$ rate & M & $\mathrm{kg} / \mathrm{tFe}$ & 184.72 \\
\hline Oxygen consumption in combustion per ton iron & $\mathrm{C}_{\text {CBT_coke }}$ & $\mathrm{kg} / \mathrm{tFe}$ & 123.35 \\
\hline Carbon consumption by direct reduction per ton iron & $\mathrm{C}_{d F e}$ & $\mathrm{~kg} / \mathrm{tFe}$ & 105.65 \\
\hline Total volume of hot air coming into the blast furnace per minute & $\mathrm{V}_{H B}$ & $\mathrm{Nm}^{3} / \mathrm{min}$ & 6748.11 \\
\hline Ratio of $\mathrm{H}_{2} \mathrm{O}$ in hot air & $\varphi\left(\mathrm{H}_{2} \mathrm{O}\right)$ & & $0.39 \%$ \\
\hline Ratio of $\mathrm{O}_{2}$ in hot air after the decomposition of $\mathrm{H}_{2} \mathrm{O}$ & $\varphi_{1}\left(\mathrm{O}_{2}\right)$ & - & $24.12 \%$ \\
\hline Ratio of $\mathrm{O}_{2}$ in hot air after the decomposition of $\mathrm{H}_{2} \mathrm{O}$ & $\varphi_{2}\left(\mathrm{O}_{2}\right)$ & - & $23.93 \%$ \\
\hline Ratio of $\mathrm{N}_{2}$ in hot air & $\varphi\left(\mathrm{N}_{2}\right)$ & - & $75.69 \%$ \\
\hline Volume of hot air needed to burn per kilogram carbon & $N_{H B}$ & $\mathrm{Nm}^{3} / \mathrm{kg}$ & 3.87 \\
\hline Volume of $\mathrm{H}_{2} \mathrm{O}$ in hot air to burn per kilogram carbon & $v_{H 2 O} O_{H B}$ & $\mathrm{Nm}^{3} / \mathrm{kg}$ & 0.015 \\
\hline Volume of $\mathrm{O}_{2}$ in hot air to burn per kilogram carbon & $v_{O 2 \_H B}$ & $\mathrm{Nm}^{3} / \mathrm{kg}$ & 0.93 \\
\hline Volume of $\mathrm{N}_{2}$ in hot air to burn per kilogram carbon & $v_{N 2} H B$ & $\mathrm{Nm}^{3} / \mathrm{kg}$ & 2.93 \\
\hline Volume of $\mathrm{CO}$ generated by burning per kilogram carbon & $v_{C O} G A S$ & $\mathrm{Nm}^{3} / \mathrm{kg}$ & 1.87 \\
\hline Volume of $\mathrm{N}_{2}$ generated by burning per kilogram carbon & $v_{N 2} G A S$ & $\mathrm{Nm}^{3} / \mathrm{kg}$ & 2.93 \\
\hline Volume of $\mathrm{H}_{2}$ generated by burning per kilogram carbon & $v_{H 2} 2_{G A S}$ & $\mathrm{Nm}^{3} / \mathrm{kg}$ & 0.009 \\
\hline Volume of $\mathrm{H}_{2} \mathrm{O}$ generated by burning per kilogram carbon & $v_{H 2 O \_G A S}$ & $\mathrm{Nm}^{3} / \mathrm{kg}$ & 0.006 \\
\hline $\begin{array}{l}\text { Thermal revenue by burning per kilogram carbon in high-temperature } \\
\text { zone }\end{array}$ & $\mathrm{q}_{C_{-} C B T}$ & $\mathrm{~kJ} / \mathrm{kg}(\mathrm{C})$ & 10308.33 \\
\hline Thermal revenue by burning per kilogram carbon while burning coke & $\mathrm{q}_{C_{-} C B T_{-} \text {coke }}$ & $\mathrm{kJ} / \mathrm{kg}(\mathrm{C})$ & 10223.32 \\
\hline Thermal revenue by burning per kilogram coal while burning coal & $\mathrm{q}_{\text {coal }}$ & $\mathrm{kJ} / \mathrm{kg}$ & 6561.37 \\
\hline Thermal consumption of per kilogram carbon directly reduced & $\mathrm{q}_{d F e}$ & $\mathrm{~kJ} / \mathrm{kg}(\mathrm{C})$ & 12746.92 \\
\hline Heat loss per ton iron & $\mathrm{Q}_{\text {loss }}$ & $\mathrm{kJ} / \mathrm{tFe}$ & 214481.47 \\
\hline Slag-iron heat index & $\mathrm{Q}_{\text {heat }}$ & $\mathrm{kJ} / \mathrm{tFe}$ & 720564 \\
\hline
\end{tabular}

Table 3: Amount of coal needed when the operating parameters of the blast furnace are changed.

\begin{tabular}{cccc}
\hline Item & Units & Operating parameters changed & Amount of coal needed $(\mathrm{t} / \mathrm{h})$ \\
\hline Blast volume & $\mathrm{Nm}^{3} / \mathrm{min}$ & +100 & +1.03 \\
Rich oxygen flow & $\mathrm{Nm}^{3} / \mathrm{h}$ & +1000 & +0.82 \\
Atmospheric humidity & $\mathrm{g} / \mathrm{m}^{3}$ & +10 & +0.50 \\
Humidification quantity & $\mathrm{t} / \mathrm{h}$ & +1 & +0.35 \\
Coke rate & $\mathrm{kg} / \mathrm{tFe}$ & +10 & -4.27 \\
\hline
\end{tabular}

time direct reduction of heat consumption is constant. Therefore, simultaneous equations (37), (38) and (39), with such parameters as estimated fuel rate, quantity of coal needed, estimated yield and $\eta_{c o}$ can be obtained for different temperatures, and the calculation results are shown in Figure 2 and Figure 3.
The furnace heat prediction model can be used to calculate the temperature of molten iron while the operation parameters of blast volume, $\eta_{C O}$, and operation yield change simultaneously. The slag-iron heat index, which is $693976 \mathrm{~kJ} / \mathrm{tFe}$, can be calculated for the following conditions: blast volume is $6196 \mathrm{Nm}^{3} / \mathrm{min}$, rich oxygen flow is 


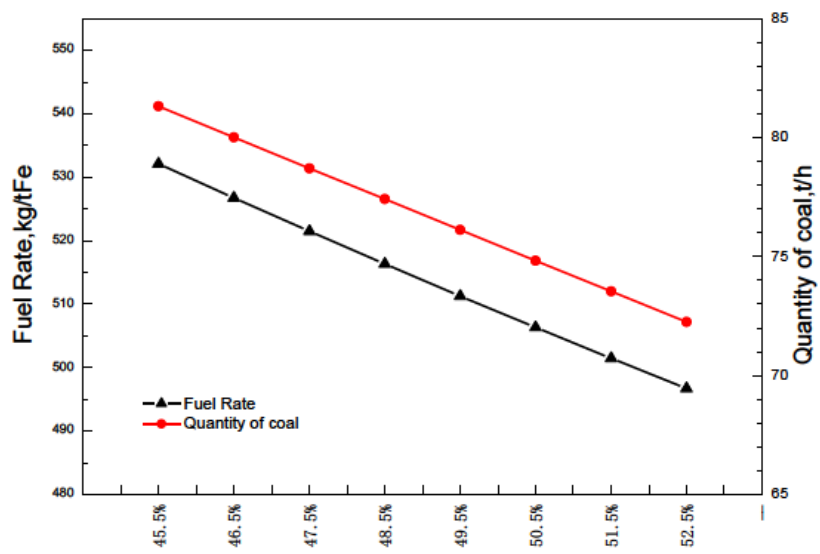

Figure 1: Estimated fuel rate and quantity of coal needed on different $\eta_{C O}$

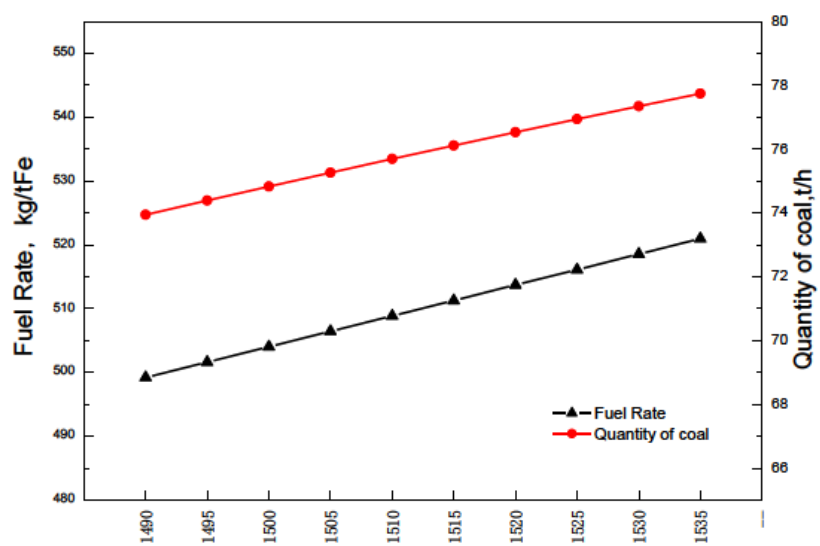

Figure 2: Estimated fuel rate and quantity of coal needed at different temperature.

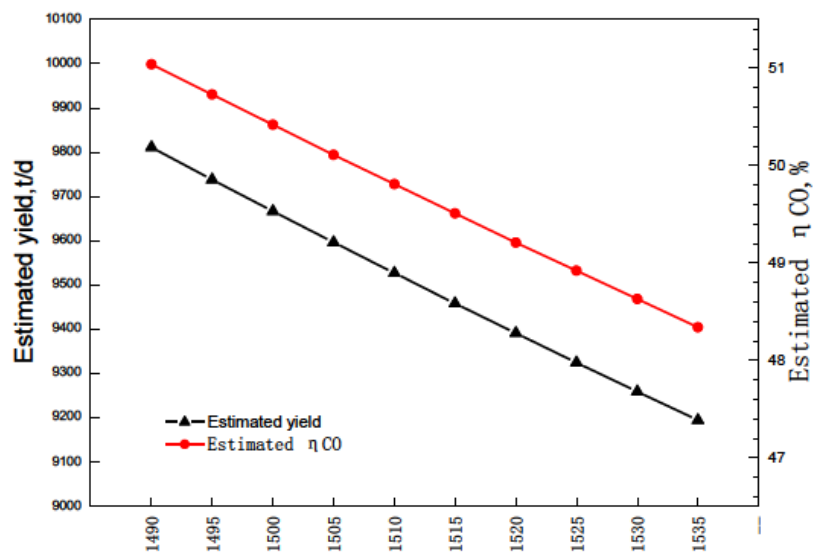

Figure 3: Estimated yield and $\eta_{C O}$ at different temperature.

$16929 \mathrm{Nm}^{3} / \mathrm{min}$, atmospheric humidity is $13.00 \mathrm{~g} / \mathrm{m}^{3}$, humidification quantity is $1.10 \mathrm{t} / \mathrm{h}, \eta_{C O}$ is $50.51 \%$, coke rate is $336.56 \mathrm{~kg} / \mathrm{tFe}$, operation yield is $9558.72 \mathrm{t} / \mathrm{d}$, and estimated molten iron temperature is $1507^{\circ} \mathrm{C}$.
By adopting the furnace heat prediction and control model, the qualified rate of hot metal temperature in a TISCO large blast furnace $\left(\mathrm{T}=1495 \sim 1515^{\circ} \mathrm{C}\right)$ increased from $60.5 \%$ to $76.7 \%$, and the qualified rate of [Si] in hot metal (the ratio of [Si] in hot metal $<0.55 \%$ ) increased from $62.9 \%$ to $68.7 \%$, which were good results.

\section{Summary}

When designing the furnace heat prediction and control model, parameters with good reliability to should be chosen, to avoid using less accurate parameters and to ensure the accuracy and practicality of the model. This paper presents an effective method for blast furnace temperature prediction and control.

1. The primary factors that influence blast furnace heat include blast parameters, coke load, gas utilization ratio, operation yield, quality of raw materials and fuel, heat load, and furnace dust. Using the furnace heat control model proposed in this paper, furnace heat parameters can be calculated when the above mentioned conditions are changed.

2. By using the thermal equilibrium and carbonoxygen balance equation for the blast furnace hightemperature zone, the slag-iron heat index which represent the heat level of the blast furnace can be calculated.

3. Using the relation between the molten iron temperature and slag-iron heat index, the furnace heat parameters can be calculated when production conditions are changed, which can guide furnace heat control.

\section{References}

[1] M.S. Chu, Modelling on Blast Furnace Process and Innovative Technologies, Northeast University Press, Shenyang, 2006.

[2] J.C. Song, Blast Furnace Iron of Theory and Operation, Metallurgical Industry Press, Beijing, 2005 (in Chinese).

[3] X.G. Bi, Mathematical Model and Computer Control of Blast Furnace Process, Metallurgical Industry Press, Beijing, 1996 (in Chinese).

[4] X.G. Liu, F. Liu, Blast Furnace Ironmaking Process Optimization and Intelligent Control System, Metallurgical Industry Press, Beijing, 2003 (in Chinese).

[5] S.R. Na, Analysis of Ironmaking Calculation, Metallurgical Industry Press, Beijing, 2010, 297-321 (in Chinese).

[6] S.R. Na, Ironmaking Calculation, Metallurgical Industry Press, Beijing, 2005, 258-275 (in Chinese). 
[7] L. Wei, S.S. Yang, F. Zhang, Q. Bai, Mathematical Model for Predicting Silicon content and Hot Metal Temperature of Blast Furnace Molten Iron by Means of Furnace Heat Index, Metallurgical Research Center, Beijing, 2005.

[8] C.X. Cao, G.Y. Zhang, Prediction System of Silicon Content in Blast Furnace Molten Iron Based on Furnace Heat Index and BP Network, Chongqing University, Chongqing, 2008.
[9] Y.Q. Huang, Prediction System of Blast Furnace Thermal State Based on Furnace Heat Index and RBF, Chongqing University, Chongqing, 2007.

[10] S. P. Mehrotta, C. Nand, ISIJ Int. 33(1993) 839-844. 